\title{
PRIAPISMO E DOENÇA FALCIFORME: PREVALÊNCIA, FATORES DE RISCO E COMPLICAÇÕES
}

\author{
Mateus Andrade Alvaia ${ }^{1}$; Jose de Bessa Junior²; Heros Aureliano Antunes da Silva \\ Maia $^{3}$; Alana de Medeiros Nelli ${ }^{4}$ e Evanilda Souza de Santana Carvalho ${ }^{5}$ \\ 1. Bolsista PIBIC/FAPESB, Graduando em Medicina, Universidade Estadual de Feira de Santana, e-mail: \\ mateus alvaia@hotmail.com \\ 2. Orientador, Departamento de Saúde, Universidade Estadual de Feira de Santana, e-mail: josedebessa@ gmail.com \\ 3. Participante do Núcleo interdisciplinar de estudos sobre desigualdades em saúde (NUDES), Departamento de Saúde, \\ Universidade Estadual de Feira de Santana, e-mail: herosmaia@hotmail.com \\ 4. Participante do Núcleo interdisciplinar de estudos sobre desigualdades em saúde (NUDES), Departamento de Saúde, \\ Universidade Estadual de Feira de Santana, e-mail: medeirosnelli@gmail.com \\ 5. Coordenadora do Núcleo interdisciplinar de estudos sobre desigualdades em saúde (NUDES), Departamento de Saúde, \\ Universidade Estadual de Feira de Santana, e-mail: evasscarvalho@yahoo.com
}

PALAVRAS-CHAVE: Doença falciforme, priapismo, disfunção sexual.

\section{INTRODUÇÃO}

A doença falciforme (DF) é reconhecida pela Organização Mundial da Saúde (OMS) como um grave problema de saúde pública mundial, com grande impacto na morbimortalidade da população afetada (Brasil, 2015). É uma doença genética, predominante entre negros e pardos e sua fisiopatologia está relacionada à ocorrência de vaso-oclusões, principalmente em pequenos vasos, determinante na origem da maioria dos sinais e sintomas da Doença (Felix; Souza; Ribeiro, 2010). No Brasil Estima-se que entre 25 a 50 mil brasileiros convivam com a DF. O estado da Bahia possui a maior incidência da doença, com uma proporção de um para cada 650 nascidos vivos, seguido dos estados do Rio de Janeiro e Minas Gerais com um para cada 1300 e 1400 respectivamente (Brasil, 2015).

De acordo com o tipo de alteração presente na hemoglobina, pode-se classificar essa hemoglobinopatia em formas clínicas distintas: forma homozigótica SS, que é a anemia falciforme (HbSS), e as formas heterozigóticas, representadas pelas associações de $\mathrm{HbS}$ com outras variantes de hemoglobinas, tais como: $\mathrm{HbC}$ e as interações com as talassemias (Felix; Souza; Ribeiro, 2010). Dentre as inúmeras repercussões clínicas agudas e crônicas da DF destaca-se o priapismo e disfunção erétil (DE) que pode acometer a população masculina.

O priapismo é um distúrbio clínico caracterizado pela ereção peniana prolongada na ausência de interesse sexual ou desejo (Burnett et al., 2014). É uma condição rara com incidência geral de 1,5 caso por 100000 pessoas. No entanto, é uma importante emergência urológica, porque o dano no tecido erétil pode levar à perda de ereções funcionais (Ekeke, O. N., Omunakwe, H. E., \& Eke, N., 2015 \& Ugwumba et al., 2016). Esta doença afeta todos os grupos etários, no entanto, a incidência é mais alta entre os pacientes com hemoglobinopatias, em que é de até 3,6\% em pacientes com idade inferior a 18 anos, aumentando para $42 \%$ em pacientes com mais de 18 anos (Ahmed et al. 2017).

A duração dos episódios representa o preditor mais significante para a manutenção adequada da função erétil. Por isso o priapismo isquêmico é condição emergencial e intervenções deveriam ser iniciadas dentro de quatro a seis horas visando detumescência dos corpos cavernosos, diminuição da dor e prevenção da DE (Salonia et al., 2013).

Episódios de priapismo "maiores" muitas vezes deixam sequela devastadora da necrose do tecido erétil e posterior fibrose pela proliferação de fibroblastos. A DE é previsível, uma vez 
que ocorre danos irreversíveis no tecido erétil, com taxas documentadas de até $90 \%$ para o priapismo com duração superior a 24 horas. No entanto, os relatos de DE também podem ser relacionados a episódios de priapismo isquêmico "menor", em que a duração dos episódios é de minutos a poucas horas (Anele et al., \& Burnett, 2015). Juntamente com a DE o priapismo reverbera na saúde mental com sentimentos de desespero, ansiedade, constrangimento e isolamento, implicando diretamente na insatisfação em relação à vida sexual.

Não existe um tratamento farmacológico que previna diretamente o priapismo, contudo medicamentos anti vaso-oclusivos podem trazer benefícios. A hidroxiureia destaca-se como o único fármaco que, efetivamente, teve impacto na melhora da qualidade de vida dos pacientes com DF, reduzindo o número de crises vaso-oclusivas (Cançado et al., 2009). Além disso, estudos como o de Anele et al. (2014), sugeriu um possível efeito da hidroxiureia na recuperação da função erétil após a resolução do priapismo.

O objetivo desse estudo é avaliar aspectos epidemiológicos do priapismo em pacientes com DF, e o impacto do mesmo na função sexual dos adultos.

O grande número de afrodescendentes no estado da Bahia e a presença de um centro de saúde referência em pessoas com DF na cidade de Feira de Santana incita a necessidade de conhecer o perfil dos falcêmicos, com destaque para os homens. A compreensão destes aspectos possibilitará uma melhor abordagem do tratamento destas condições, permitirá a elaboração de políticas públicas mais realistas e minimizará os agravos associados a tão grave condição.

\section{MATERIAL E MÉTODOS OU METODOLOGIA (ou equivalente)}

Trata-se de um estudo transversal observacional (cross-sectional) onde foram avaliados pacientes masculinos com DF acompanhados em Centro de referência em Feira de Santana Bahia entre outubro de 2016 e junho de 2017.

Após assinatura do Termo de Consentimento Livre e Esclarecido TCLE em conformidade com a Resolução 466/12, os sujeitos responderam a um questionário estruturado acerca das características sociodemográficas e referentes ao eventual priapismo: presença, frequência, duração, recorrência, desencadeadores e tratamentos. Para comparações os priapismos foram classificados como menores ou maiores de acordo com a frequência e duração dos episódios. O priapismo foi considerado grave (major) quando de duração igual ou maior do que 4 horas e menor quando de duração inferior a 4 horas.

A função erétil nos adultos sexualmente ativos foi avaliada a partir de uma escala numérica (de zero à 10) e pelos questionários validados Erection Function Score (EFS), Erection Hardness Score (EHS) e o International Index of Erectile Function-5 (IIEF-5). No IIEF-5, pacientes com escores 22 serão considerados sem DE, entre 17 e 21 com DE mínima, entre 8 e 16 como moderada e menor do que 7 com DE grave. No EFS o entrevistado escolheu a opção que melhor qualifica sua ereção que variava de um (normal, completamente ereto) à cinco (sem ereção). Já no EHS o paciente apontava no dispositivo qual o grau da sua ereção.

A satisfação com a vida sexual também foi avaliada através da opção que melhor se adequava a sua realidade, que variavam entre muito insatisfeito e muito satisfeito. Foi utilizado também uma escala pictográfica para esta avaliação.

As variáveis quantitativas, contínuas ou ordinais, foram descritas por suas medidas de tendência central (médias ou medianas) e pelas respectivas medidas de dispersão (desviopadrão, variação interquartil ou valores mínimo e máximo), enquanto as nominais ou qualitativas por seus valores absolutos, percentagens ou proporções. Para comparação das diferenças das variáveis contínuas, utilizamos o teste t de Student e o teste de Mann-Whitney. 
Teste de D'Agostino - Pearson foi empregado na avaliação do padrão de distribuição das variáveis.

Na comparação dos dados categóricos, utilizou-se os testes de Fisher ou do quiquadrado e suas variantes.

A associação entre os parâmetros estudados foi expressa pela razão de prevalência ou Odds Ratio. Intervalos de confiança de $95 \%$ foram empregados como medidas de precisão dos resultados. Valores de $\mathrm{p}$ menores que $0,05(\mathrm{p}<0,05)$ foram considerados significativos. Nas análises foi utilizado o programa estatístico computacional GraphPad Prism, versão 6.0.3,GraphPad Software, San Diego-CA, USA.

\section{RESULTADOS E/OU DISCUSSÃO}

A amostra deste estudo foi composta por 42 indivíduos do sexo masculino, sendo que $64,28 \%$ (27/42) desses possuem genótipo HbSS, 26,19\% (11/42) HbSC, 2,38\% (1/42) S $\alpha$-thal e 7,14\% (3/42) não souberam responder. A idade dos sujeitos entrevistados foi de 26,43 $\pm 12,11$ anos. 59,5\% dos indivíduos desconheciam o significado de priapismo. Após esclarecimento, foi possível verificar uma prevalência de $42,85 \%$ (18/42) nessa amostra.

Em relação ao genótipo, 72,22\% (13/18) dos entrevistados que tiveram priapismo são $\mathrm{HbSS}, 22,22 \%$ (4/18) são HbSC e um deles não soube informar. Dos que apresentaram priapismo major, $75 \%$ (6/8) eram $\mathrm{HbSS}$ e $25 \%$ (2/8) HbSC.

$72,22 \%$ (13/18) dos episódios se iniciaram no turno noturno (noite e madrugada) e o frio foi o fator precipitante em 27,77\% (5/18) das vezes. 50\% (9/18) referiram ida a serviço de emergência por causa do priapismo.

O episódio mais precoce ocorreu aos 6 e o mais tardio aos 40 anos. Percebeu-se também que 44,44\% (8/18) apresentaram a forma grave (major). Além disso, episódios menores, recorrentes, foram a apresentação inicial em 83,33\% (15/18) dos casos de priapismo.

No que se refere ao uso de medicações, todos os pacientes entrevistados utilizam folato, mas somente 35,71\% (15/42) fazem uso de hidroxiureia. Desses 53,33\% (8/15) já apresentaram algum episódio de priapismo. Ao considerar somente os homens que referiram priapismo, 44,4\% (8/18) fazem uso dessa medicação.

Pacientes com episódios de priapismo graves (PG) apresentaram ereção significativamente pior: EHS=4 [3-4] em pacientes sem PG e EHS=2[1-3] em pacientes com PG ( $\mathrm{p}=0,0124)$. Quanto ao EFS, pacientes com PG também apresentaram função erétil pior: $\mathrm{EFS}=1$ [1-2] em homens sem PG e EFS=3 [1-4] em homens com PG (p=0,0104). Já em relação à satisfação com a vida sexual (SVS), pacientes com episódios graves estão menos satisfeitos: $\mathrm{SVS}=3$ [3-5] em indivíduos sem $\mathrm{PG}$ e $\mathrm{SVS}=2$ [1-2] em indivíduos com $\mathrm{PG}$ ( $\mathrm{p}=0,0202)$

\section{CONSIDERAÇÕES FINAIS}

A prevalência de priapismo identificada nesse estudo corrobora com os valores encontrados na literatura. O genótipo HbSS esteve profundamente relacionado com os episódios de priapismo, com destaque para os episódios graves. O priapismo manifesta-se inicialmente na maioria das vezes como episódios intermitentes/menores já na infância e adolescência. Os episódios "maiores" e mais graves estão associados diretamente a dano cavernoso e prejuízo importante na qualidade da ereção e consequentemente na função sexual da população estudada. Além disso, priapismo grave está associado também a menor satisfação com a vida sexual na idade adulta. 


\section{REFERÊNCIAS}

1. BRASIL. Ana Margareth Gomes Alves. Ministério da Saúde. Anemia Falciforme: Conhecer para cuidar. 2015. Disponível em: 〈http://telelab.aids.gov.br>.

2. FELIX, A. A.; SOUZA, H. M.; RIBEIRO, S. B. F. Aspectos epidemiológicos e sociais da doença falciforme. Rev. Bras. Hematol. Hemoter. São Paulo . 32(3): 203-208.

3. BRASIL. F. R. Agência Saúde. Doença Falciforme: Pessoas com a doença poderão fazer transplante de medula. 2015. Disponível em: 〈http://portalsaude.saude.gov.br >.

4. BURNETT, A. L. et al. Randomized Controlled Trial of Sildenafil for Preventing Recurrent Ischemic Priapism in Sickle Cell Disease. Am J Med. Baltimore. 127(7): 664-668.

5. EKEKE, O. N., OMUNAKWE, H. E., \& EKE, N. 2015. Management of Priapism in Adult Men. International Surgery, 100 (3), 552-557.

6. UGWUMBA, F.O. et al. Ischemic priapism in South-East Nigeria: Presentation, management challenges, and aftermath issues. Nigerian Journal Of Clinical Practice. Enugu State. 19(2): 207-211.

7. AHMED, Muhammed et al. Prognostic factors and outcome of management of ischemic priapism in Zaria, Nigeria. Nigerian Journal Of Surgery. Zaria. 23(1): 15-19.

8. SALONIA, A. et al. European Association of Urology Gidlines on Priapism. European Urology. Milão. 65(1): 480-489.

9. ANELE, Uzoma A. et al. Hydroxyurea therapy for priapism prevention and erectile function recovery in sickle cell disease: a case report and review of the literature. Int Urol Nephrol. Baltimore. 46(9): 1733-1736.

10. CANCADO, R. D. et al. Protocolo clínico e diretrizes terapêuticas para uso de hidroxiureia na doença falciforme. Rev. Bras. Hematol. Hemoter. São Paulo. 31(5): 361-366. 